\title{
The Long-term Structural Plasticity of Cerebellar Parallel Fiber Axons and Its Modulation by Motor Learning
}

\author{
Jennifer Carrillo, ${ }^{1 \star}$ Shao-Ying Cheng, ${ }^{2 \star}$ Kwang Woo Ko, ${ }^{1 \star}$ Theresa A. Jones, ${ }^{2}$ and Hiroshi Nishiyama ${ }^{1}$ \\ ${ }^{1}$ Center for Learning and Memory and ${ }^{2}$ Department of Psychology, University of Texas at Austin, Austin, Texas 78712
}

Presynaptic axonal varicosities, like postsynaptic spines, are dynamically added and eliminated even in mature neuronal circuitry. To study the role of this axonal structural plasticity in behavioral learning, we performed two-photon in vivo imaging of cerebellar parallel fibers (PFs) in adult mice. PFs make excitatory synapses on Purkinje cells (PCs) in the cerebellar cortex, and long-term potentiation and depression at PF-PC synapses are thought to play crucial roles in cerebellar-dependent learning. Time-lapse vital imaging of PFs revealed that, under a control condition (no behavioral training), $\sim 10 \%$ of PF varicosities appeared and disappeared over a period of 2 weeks without changing the total number of varicosities. The fraction of dynamic $P F$ varicosities significantly diminished during training on an acrobatic motor skill learning task, largely because of reduced addition of new varicosities. Thus, this form of motor learning was associated with greater structural stability of PFs and a slight decrease in the total number of varicosities. Together with prior findings that the number of PF-PC synapses increases during similar training, our results suggest that acrobatic motor skill learning involves a reduction of some PF inputs and a strengthening of others, probably via the conversion of some preexisting PF varicosities into multisynaptic terminals.

\section{Introduction}

Adaptive changes in synaptic properties are crucial for learning and memory in the mammalian brain. These changes involve not only functional modulations of existing synapses but also structural rewiring of neuronal circuitry through formation and elimination of synaptic connections. Recent studies using two-photon in vivo microscopy have revealed that novel sensory experience and motor learning promote formation and elimination of dendritic spines in the adult neocortex (Zuo et al., 2005a; Holtmaat et al., 2006; Xu et al., 2009; Yang et al., 2009). In addition, stable maintenance of new spines is suggested to underlie long-term memory formation ( $\mathrm{Xu}$ et al., 2009; Yang et al., 2009).

Newly formed spines have been shown to make synaptic contact with presynaptic axon terminals (Knott et al., 2006). However, new axon terminals are not necessarily formed because the newly formed spines may instead form contacts with existing presynaptic terminals. Presynaptic axons, like postsynaptic dendrites and spines, show dynamic structural changes in the adult brain even without any unusual sensory or behavioral stimula-

Received Aug. 7, 2012; revised April 3, 2013; accepted April 5, 2013.

Author contributions: T.A.J. and H.N. designed research; J.C., S.-Y.C., K.W.K., and H.N. performed research; J.C., S.-Y.C., and H.N. analyzed data; J.C., S.-Y.C., T.A.J., and H.N. wrote the paper.

This work was supported by the University of Texas at Austin (startup funds), Whitehall Foundation, and National Institutes of Health Grant NS073919 to H.N. and Grant NS056839 to T.A.J., S.-Y.C. was supported by the American Heart Association Postdoctoral Fellowship 12P0ST9180003. We thank Dr. Boris Zemelman for providing the AAV1 vector and Dr. Miguel Sena-Esteves for providing the AAV8 vector.

The authors declare no competing financial interests.

*J.C., S.-Y.C., and K.W.K. contributed equally to this work.

Correspondence should be addressed to Dr. Hiroshi Nishiyama, Center for Learning and Memory, University of Texas at Austin, 1 University Station, Stop C7000, Austin, TX 78712. E-mail: hiroshi@utexas.edu.

DOI:10.1523/JNEUROSCI.3792-12.2013

Copyright $\odot 2013$ the authors $\quad 0270-6474 / 13 / 338301-07 \$ 15.00 / 0$ tion (De Paola et al., 2006; Majewska et al., 2006; Stettler et al., 2006; Nishiyama et al., 2007). Furthermore, rapid axonal sprouting and pruning occur upon sensory deprivation (Yamahachi et al., 2009). Nevertheless, the extent to which presynaptic structural plasticity plays a role in learning-induced rearrangements of synaptic circuitry remains largely unknown. Understanding axonal structural changes in relation to learning is fundamentally important because axons usually span many millimeters and make synaptic contacts with diverse postsynaptic targets, suggesting that axonal structural changes, if they occur, may cause profound rewiring of functional circuitry.

However, investigating the role of presynaptic structural plasticity in learning has been complicated by the fact that: (1) most brain regions receive heterogeneous axonal inputs coming from diverse presynaptic origins; and (2) with such complex circuitry, it is generally difficult to identify which synaptic connections are involved in an observed learning event. The cerebellar cortex is especially a useful model to overcome these technical limitations because of its well-defined circuitry. Purkinje cells (PCs) in the cerebellar cortex integrate sensorimotor information and modulate the animal's ongoing movement by changing their inhibitory drive in the deep cerebellar nucleus (Ito, 1984). PCs receive inhibitory GABAergic inputs from local interneurons (INTs) and excitatory glutamatergic drive from two inputs, parallel fibers (PFs) and climbing fibers (CFs). Previous electron microscopy studies have shown that acrobatic motor skill learning induces structural alteration of postsynaptic PC spines and selectively increases the number of PF-PC synapses per PC without changing either CF-PC or INT-PC synapses (Kleim et al., 1998; Lee et al., 2007). However, it remains unknown whether the learninginduced increase of PF-PC synapses is associated with structural remodeling of presynaptic PF terminals. 
To study the dynamic structural plasticity of PF terminals, we sparsely labeled them with EGFP. The labeled PFs were repeatedly imaged in vivo over the period of a few weeks to almost 11 months under the control condition and acrobatic motor skill learning task.

\section{Materials and Methods}

Surgery. All procedures were approved by the Institutional Animal Care and Use Committee of the University of Texas at Austin. To label PFs, the serotype 1 and 8 of adeno-associated virus (AAV) that expresses EGFP under the control of a CBA promoter (a hybrid promoter that consisted of the cytomegalovirus enhancer element and chicken $\beta$-actin promoter) were used. The AAV1, prepared as described previously (Grieger et al., 2006), and AAV8 (Broekman et al., 2006) were generously provided by Dr. Boris Zemelman of University of Texas at Austin and Dr. Miguel Sena-Esteves of University of Massachusetts, respectively. The intraparenchymal injections of AAV were performed on adolescent male C57BL/6 mice (4-6 weeks old) as described previously (Nishiyama et al. (2007), except that injections were made near the border between the cerebellar vermal lobule VII and the paramedian lobule in the right cerebellar hemisphere. The virus was injected at a depth of 300 and $700 \mu \mathrm{m}$ from the dura mater. The total volume of injection varied per animal, and the range was between 9.2 and $160 \mathrm{nl}$. The pipette was withdrawn 5 min after the injection, and the skin was sutured. The mouse was returned to the home cage after the surgery.

At least 3 weeks after the virus injection, a cranial window was prepared as described previously (Nishiyama et al., 2007), except that: (1) the window was prepared on the paramedian lobule and (2) a coverslip was placed directly on top of the dura, and the surgical cyanoacrylate was applied to the edge of the craniotomy to avoid bone regeneration. Dental cement was then applied around the coverslip and on the exposed skull surface to create a cranial window. After the surgery, the mice were returned to their home cages. Although this surgery induced minor and transient brain inflammatory responses, the inflammation subsided within 2 weeks (data not shown). It has been shown that such a cranial window is not associated with altered neuronal structural plasticity (Holtmaat et al., 2009).

In vivo two-photon microscopy. After at least 2 weeks of recovery from the cranial window preparation, in vivo two-photon microscopy was performed as described previously (Nishiyama et al., 2007) using a laserscanning confocal microscope (FV1000MPE, Olympus) equipped with a $25 \times$ water-immersion objective lens (Olympus XLPlanN, $1.05 \mathrm{NA}$ ) and external, nondescanned photomultiplier tubes. For two-photon excitation of EGFP, $920 \mathrm{~nm}$ of pulsed laser was provided by Mai Tai HP DeepSee mode-locked Ti:sapphire laser (Spectra-Physics). The emitted fluorescence was reflected by a dichroic mirror (DM570) and then filtered by a bandpass filter (BA495-540) before detection by the external photomultiplier tubes. The $z$-stack images (spaced $1 \mu \mathrm{m}$ apart) of the cerebellar molecular layer were taken in the paramedian lobule where individual PFs and their varicosities were clearly resolved. One to four different ROI were imaged per animal with high resolution $(0.16 \mu \mathrm{m} /$ pixel in most of the images). The $x-y$ dimension of each ROIs ranged between $85 \times 85$ to $170 \times 170 \mu \mathrm{m}^{2}$. After image acquisition, the animal was allowed to recover from the anesthesia and returned to the home cage.

Analysis of PF structural plasticity. The PF images were transferred to $\mathrm{NIH}$ ImageJ (http://rsb.info.nih.gov/ij/) and processed with a median filter (1 pixel radius) to reduce shot noise in each optical plane. The PF varicosities were identified in raw $z$-stacks, and their time-lapse changes between two consecutive time points were classified in one of three groups: stable, appeared, and disappeared. Because small and/or weakly labeled varicosities tend to show artifactual structural changes when there is a slight difference in labeling intensity between two time points, we analyzed only PF varicosities $>0.8 \mu \mathrm{m}^{2}$ and 2.5 times brighter than the adjacent axonal backbone. It should be noted that we most likely overestimated the varicosity size because our fluorescence excitation/ detection settings were set to clearly visualize fine caliber axons, which tend to correct more than sufficient signals from varicosities.
To compare the size of stable and dynamic (i.e., appeared or disappeared) varicosities, the size of same varicosities was measured at multiple time points and the mean (i.e., temporal average of the size of each varicosity) was calculated. This mean was used for the comparison because the size measurement is affected by various experimental factors (e.g., labeling intensity and brain pulsation) that may change from imaging session to session.

Acrobatic motor skill learning task. Acrobatic motor skill training was modified from the task used for rats (Black et al., 1990; Kleim et al., 1998; Jones et al., 1999). The mice were required to sequentially traverse elevated obstacles leading to their home cage. The obstacles included 12 wooden platforms with different heights and $5 \mathrm{~cm}$ apart, a wide rod $(2 \mathrm{~cm}$ diameter), a narrow rod ( $1 \mathrm{~cm}$ diameter $)$, rope $(0.5 \mathrm{~cm}$ diameter $)$, parallel ropes $(0.6 \mathrm{~cm}$ diameter, $4 \mathrm{~cm}$ apart), parallel rubber bands $(0.1 \mathrm{~cm}$ diameter, $2 \mathrm{~cm}$ apart $)$, a metal link chain $(2.3 \times 6.7 \mathrm{~cm}$ link $)$, and a grid platform $(20 \times 35 \mathrm{~cm}$ with $2 \times 2 \mathrm{~cm}$ openings $)$. Millet seeds were placed in the home cage to further motivate completion of the course. For 8 consecutive weeks, mice received training on $5 \mathrm{~d}$ per week followed by 2 rest days (some of which were used for the in vivo imaging). During the first week, mice were trained for $30 \mathrm{~min}$ daily, or up to four trials (four complete traversals of the obstacle course). Thereafter, mice received six trials per day. If needed, gentle touches to the hindquarters were given to the mice during training to initiate movement (this was rarely needed after the first week of training). Performance was measured by recording the number of foot slips and the time required to finish the course as described previously (Black et al., 1990; Kleim et al., 1998; Jones et al., 1999).

The total distance that a mouse traversed during the acrobatic training was 90 feet per day. Therefore, a separate group of mice was trained to traverse the same distance by walking in a plain 4-foot-long alley (instead of elevated obstacles) back and forth. This group served as a motor activity-matched control (Jones et al., 1999).

\section{Results}

\section{Labeling and imaging of PFs in vivo}

To stably label PFs with fluorescent proteins, cerebellar granule cells were labeled with a cortical injection of AAV (serotype 1 and 8) that drives the expression of EGFP under the control of the CBA promoter. We pooled the data of both AAV serotypes because they showed a similar pattern of labeling and structural stability of PF varicosities. At least 3 weeks after the virus injection, a cranial window was made and labeled neurons in the cerebellar cortex were imaged in anesthetized mice using in vivo two-photon microscopy. Labeling intensity near the injection site was too intense to resolve individual cells or their processes in our experimental conditions. The intensely labeled area was always in the shape of a mediolaterally elongated beam, indicating that PF bundles were strongly labeled. The cellular labeling became progressively sparser as we moved the imaging field away from the injection site, and we could clearly see individual neurons and their processes (Fig. 1). Glial cells were not labeled.

The EGFP-positive structures that were remote from the injection site were mostly PFs that run transversely for $>1 \mathrm{~mm}$ and have numerous en passant varicosities (Fig. $1 A$ ). We often observed sparsely labeled PCs, INTs (basket or stellate cells), and granule cells (the origin of PFs) as well (Fig. $1 B-D$ ). Although it is unclear how PCs, INTs, and granule cells were sometimes labeled sporadically at the area far from the injection site, the clear morphological differences between these neurons and PFs allowed us to identify PFs unambiguously even when they coexisted in the same imaging field.

\section{Chronic time-lapse imaging of PFs without experimental manipulation}

At least 2 weeks after preparing the cranial window, the first imaging session was undertaken and the same PFs were repeat- 

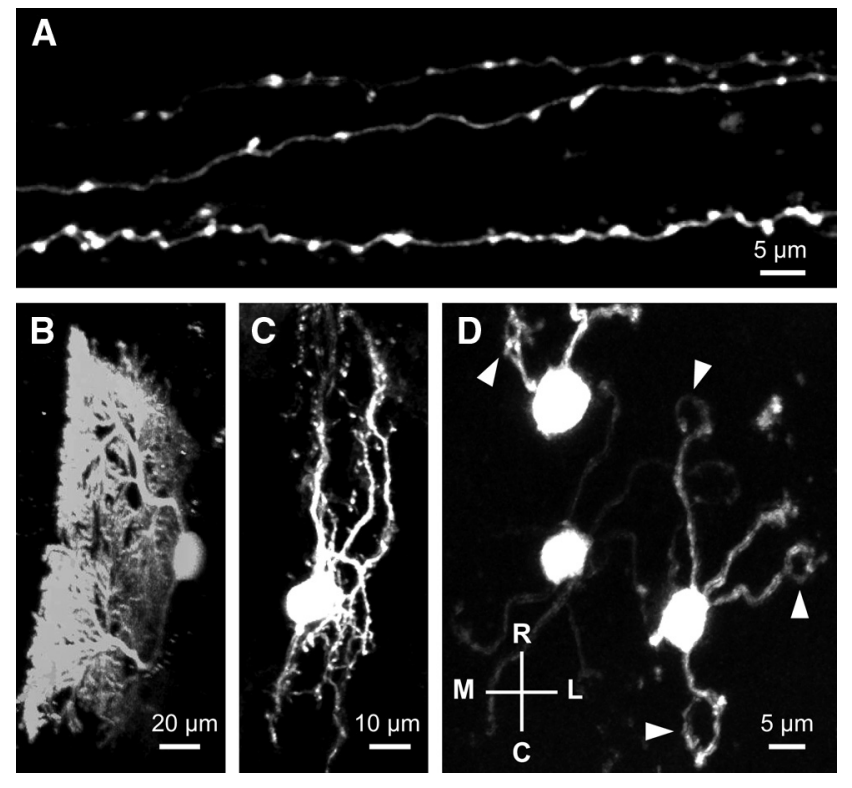

Figure 1. In vivo two-photon images of EGFP-labeled neurons in the cerebellar cortex of an adult mouse. Neurons were labeled with a cortical injection of AAV-EGFP and subsequently imaged in vivo through a cranial window. Maximum projections of parallel fibers $(\boldsymbol{A})$, Purkinje cell $(\boldsymbol{B})$, molecular layer interneuron $(\boldsymbol{C})$, and granule cells $(\boldsymbol{D})$ are shown. $\boldsymbol{B}$, The image was digitally rotated to yield a sagittal view of the Purkinje cell. $\boldsymbol{D}$, Mediolateral $(M-L)$ and rostrocaudal $(\mathrm{R}-\mathrm{C})$ axes of the images. Arrowheads indicate claw-shaped endings of granule cell dendrites.
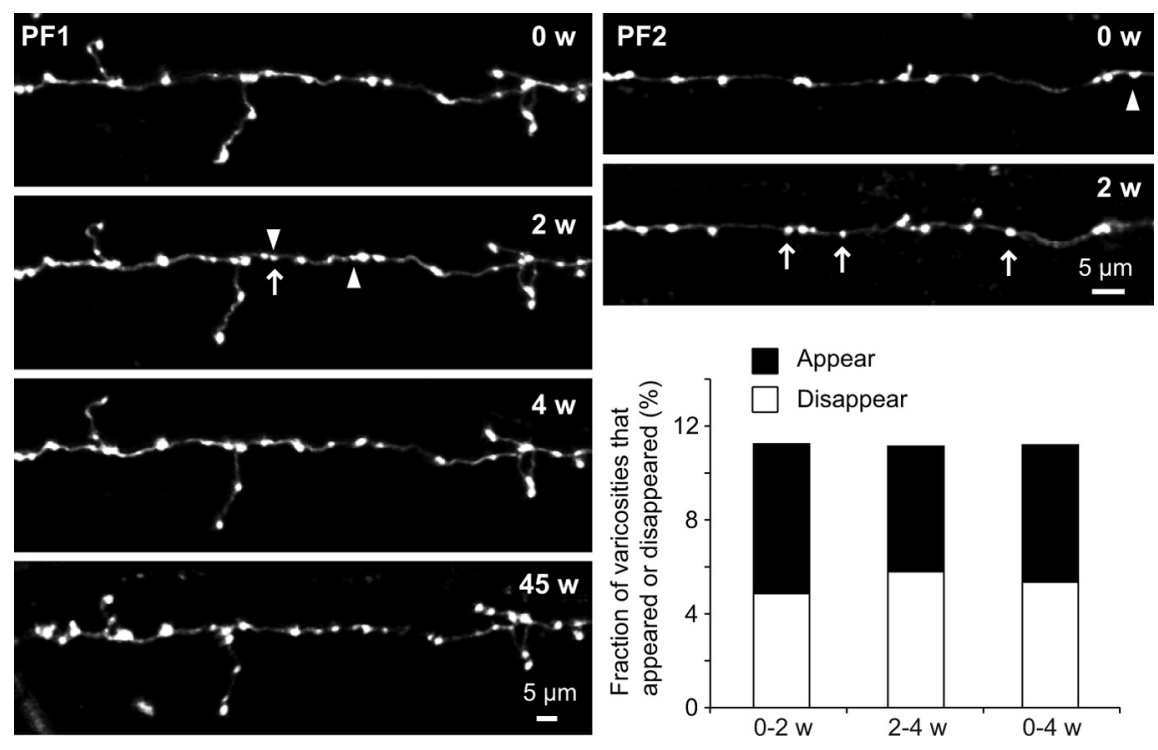

Figure 2. A small fraction of PF varicosities appears or disappears. Exemplar time-lapse images of PFs and their varicosities in two different preparations (PF1 and PF2) are shown. Overall imaging periods were 45 and 2 weeks (W) for PF1 and PF2, respectively. Arrows indicate PF varicosities that appeared in a particular imaging session. Arrowheads indicate PF varicosities that disappeared in the next imaging session. Neither an arrow nor an arrowhead is drawn in the image taken at 45 weeks because there were multiple imaging sessions between the 4 week and 45 week time points (images not shown). The histogram shows the fraction of dynamic varicosities. Only PFs that have $\geq 3$ time points $(0,2$, and 4 weeks) were analyzed and fractions of appeared and disappeared varicosities between two consecutive time points $(0-2 w, 2-4 w)$ were quantified. The fractions represented by the right bar $(0-4 \mathrm{w})$ indicate the total number of appeared and disappeared varicosities divided by total number of varicosities over this 4 week period.

edly observed at various time intervals (days to weeks) under basal conditions (without any experimental manipulation to the mice). In a short time period (within a week), they appeared to be very stable, and we barely found any noticeable changes (data not shown). However, longer-term observation ( $\geq 2$ weeks) usually revealed the appearance and disappearance of some PF varicosities. We therefore set the interval between the imaging sessions to 2 weeks (to avoid potential photo-bleaching/damage because of unnecessarily frequent observation) and analyzed the dynamic (Fig. 2). We fined as appeared or disappeared varicosities) between each two al, respectively) were dynamic within a period of 2 weeks and the numbers lost versus gained were almost balanced over the entire 4 week imaging period. These results suggest that mature PF terminals undergo continuous structural remodeling that occurs sowly, over long time scales, but without a net increase or decrease in the total number of terminals. Furthermore, dynamic $\mathrm{PF}$ varicosities were a minor fraction of the total population of varicosities, most of which were found in the same location on (Fig. 2, PF1).

\section{Chronic time-lapse imaging of PFs during acrobatic motor skill learning}

We next examined whether the formation and elimination of PF varicosities are modulated by motor learning. We used training on an acrobatic motor skill learning task that requires animals to learn whole-body coordinated movements to traverse an elevated obstacle course (Black et al., 1990; Kleim et al., 1998; Jones et al., 1999). Previous studies have shown that acrobatic training induces synaptogenesis and structural changes of PC spines broadly in the cerebellar paramedian lobule (Black et al., 1990; Kleim et al., 1998; Lee et al., 2007), a cortical region that is thought to be responsible for coordinated limb movement (Brodal, 1981).

We trained 8 mice for 8 weeks ( $5 \mathrm{~d}$ of training per week; $40 \mathrm{~d}$ of training in total): 2 served as controls and did not undergo surgery or imaging and 6 had surgeries (a virus injection and a cranial window preparation) and multiple imaging sessions before, during, and after the 8 week training period. As measured by the number of errors (foot slips) and the time (latency) required to traverse the course, animals rapidly improved their behavioral performance during the initial $10 \mathrm{~d}$ and learning slowly improved thereafter until it reached plateau at $\sim 20-30$ d (Fig. 3). Although one control mouse (without surgery) performed the task poorly compared with the other mice as measured by latency, all six experimental mice (with cranial windows) learned the task as well as the other control mouse.

These results showed that the surgeries or occasional anesthesia for imaging did not interfere with acrobatic motor skill learning in experimental mice.

Images of the same PFs in the paramedian lobule were taken 6 times during a period of 12 weeks (Fig. 4A,B). Twenty PFs from 
A
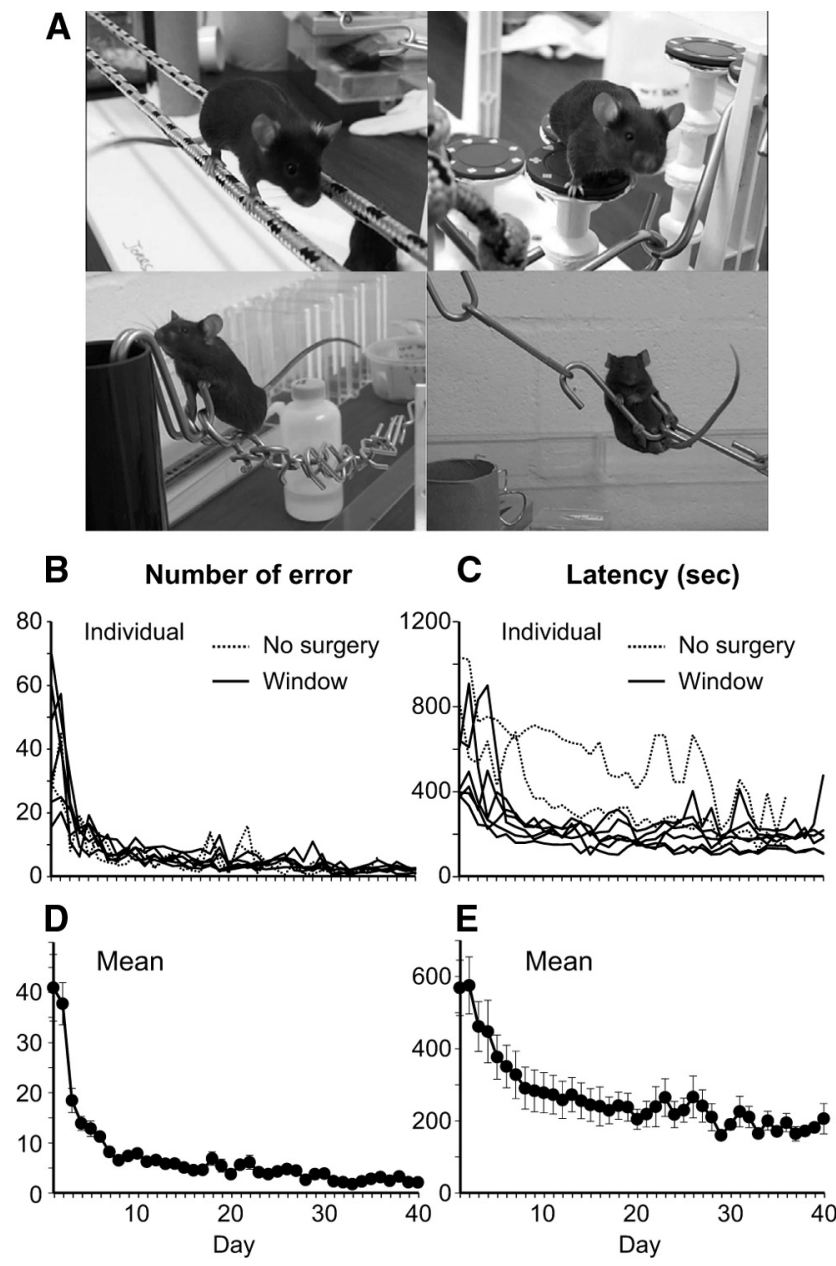

Figure 3. Mice are able to perform acrobatic motor skill learning task regardless of the presence of a cranial window and the occasional use of anesthesia for time-lapse in vivo imaging. $A$, Mice trained on the acrobatic task. The line graphs represent number of error $(B, D)$ and latency $(\boldsymbol{C}, \boldsymbol{E})$ to traverse an elevated course for acrobatic motor skill learning during the $40 \mathrm{~d}$ of training period. $\boldsymbol{B}, \boldsymbol{C}$, Individual mice. $\boldsymbol{D}, \boldsymbol{E}$, Average of all mice. Error bars represent $\mathrm{SE}$ of the mean.

6 mice that received the acrobatic training (178 PF varicosities at the first time point) were imaged, and the fraction of dynamic varicosities between every two consecutive time points were quantified before training (between imaging sessions 1 and 2), during the early phase of training (rapid learning phase: between sessions 2 and 3), intermediate phase of training (slow learning/ plateau: between sessions 3 and 4), late phase of training (after reaching plateau: between sessions 4 and 5), and after training (between sessions 5 and 6). As shown in Figure 4C, the fraction of dynamic varicosities was reduced during the early phase of training $(3.3 \%)$ compared with before training $(9.6 \%)$. Because this form of motor learning most rapidly occurs during the initial few days of training (Fig. 3), we also quantified the fraction of dynamic varicosities during this phase with a shorter imaging interval (Fig. $4 C$, inset). Although these time points were available only in a subset of our data ( 3 mice, $8 \mathrm{PFs}$ ) and the probability of observing dynamic varicosities between two consecutive time points would be decreased by the shorter imaging interval, we did not find any transient increase of dynamic varicosities during this phase. The reduced level of PF structural plasticity was maintained throughout the training period (between sessions 2-3, $3-4$, and $4-5$ ), but greater PF structural plasticity appeared to be returning in the time period after training ended (Fig. $4 C$ ). It is worth noting that the frequency of disappearance dominated the frequency of appearance throughout the training period, suggesting that acrobatic motor skill learning causes a slight decrease of the total number of PF varicosities.

To statistically analyze the reduction of PF structural plasticity during acrobatic training, a separate group of mice underwent a motor activity-matched control task (Jones et al., 1999). In this control task, mice just walked back and forth in a plain 4-footlong alley (instead of elevated obstacles) until they walked a total of 90 feet per day, the same distance that the mice traversed per day during acrobatic training. This serves as a better control than no behavioral training because locomotor activity is similar between the control task and acrobatic training; hence, the primary difference between the two groups can be considered to be whether the task involves motor skill learning or not. Time-lapse in vivo imaging was performed before and during the control task with the same schedule shown in Figure 4A, and 11 PFs from 4 mice (160 PF varicosities at the first time point) were analyzed (Fig. 4D). Before the task, the fraction of dynamic varicosities $(8.8 \%)$ did not significantly differ from that in the acrobatic training group $\left(9.6 \%, p>0.8, \chi^{2}\right.$ test). But, unlike acrobatic training, the control task did not suppress PF structural plasticity. The fraction of dynamic varicosities between sessions 2 and 3 during the control task was $8.3 \%$, and it was significantly higher than that during acrobatic training $\left(3.3 \%, p<0.05, \chi^{2}\right.$ test $)$. The fractions of dynamic varicosities between sessions $3-4$ and $4-5$ were also significantly higher in the control group than in the acrobatic training group ( $p<0.01, \chi^{2}$ test). These results strongly suggest that acrobatic motor skill learning suppresses $\mathrm{PF}$ structural plasticity during the early phase of training and the reduced level of structural plasticity is maintained throughout the training period. This is not limited to a small subset of mice. During acrobatic training, the average number of dynamic varicosities per single imaging interval was less than half of that before the training in 4 of 6 mice (Animals 2, 3, 5, and 6; Table 1). None of the mice in the motor activity-matched control group (Animals 7-10) showed a similar degree of reduction in PF structural plasticity as did the acrobatic training group. Because Animal 1 in the acrobatic training group did not show PF structural plasticity, even before the training, there should be no further reduction of structural plasticity by learning. Therefore, there was only one animal (Animal 4) that did not agree with the overall observation that acrobatic motor skill learning suppresses PF structural plasticity.

To further characterize how learning affects PF structural plasticity, we divided the varicosities into three groups: stable (were always present throughout the imaging period), preexisting-disappeared (were present at the first imaging session but disappeared later), and newly appeared (were not present at the first imaging session but appeared later). We first analyzed the size of these three different types of varicosities and found that stable ones were significantly larger than preexisting-disappeared and newly appeared ones in the control group $(p<0.05$, TukeyKramer multiple-comparison test; Fig. $5 A$ ). The stable varicosities were also significantly larger than newly appeared ones in the acrobatic training group $(p<0.05)$, but the difference between the stable and preexisting-disappeared ones was not statistically significant $(p>0.05$, Tukey-Kramer multiple-comparison test; Fig. 5A). However, the average size of preexisting-disappeared varicosities was smaller than stable ones, and the size of neither stable nor preexisting-disappeared varicosities significantly differed between the control and acrobatic training 
A
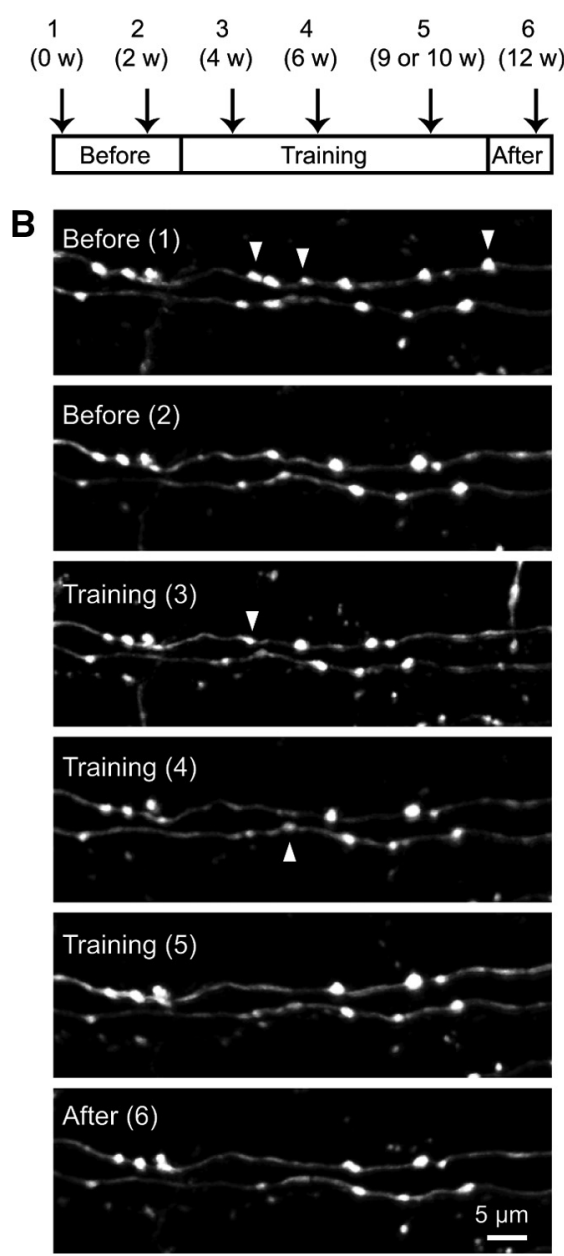
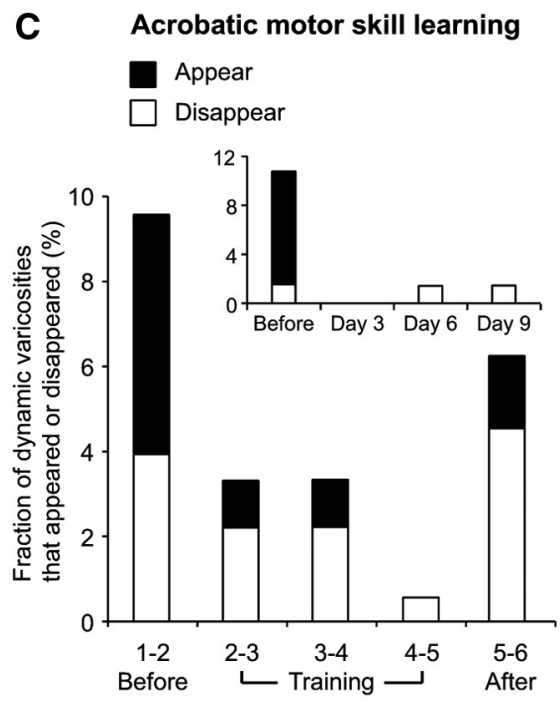

D Motor activity matched control

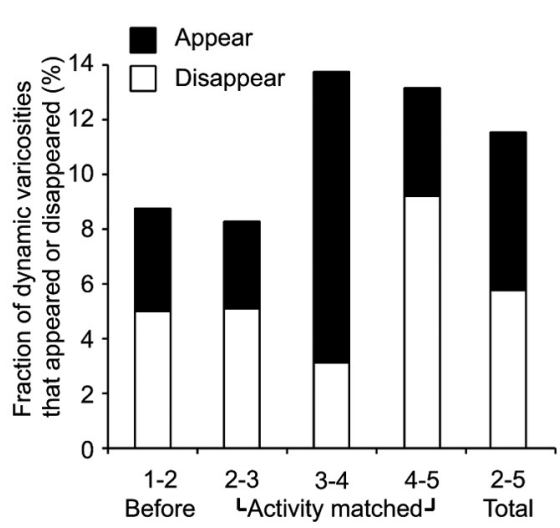

Figure 4. Acrobatic motor skill learning suppresses dynamic structural plasticity of PF varicosities. $\boldsymbol{A}$, Timeline of the experiment. $\boldsymbol{B}$, Exemplar time-lapse images of PFs and their varicosities before, during, and after the training of acrobatic motor skill learning. Arrowheads indicate PF varicosities that disappeared in the next imaging session. $\boldsymbol{C}$, The histogram represents the fraction of dynamic varicosities between two consecutive time points shown in $\boldsymbol{A}$ over the 12 week imaging period under the acrobatic motor skill learning task. Inset, $A$ fraction of dynamic varicosities during the initial $10 \mathrm{~d}$ of training. These time points are available only in a subset of PFs. $\boldsymbol{D}$, The histogram represents the fraction of dynamic varicosities between two consecutive time points over the 9 week imaging period under the motor activity-matched control task. The fractions shown on the right bar (2-5 Total) indicate the total number of appeared and disappeared varicosities divided by the total number of varicosities over this 7 week period.

groups ( $p>0.05$, Tukey-Kramer multiple-comparison test; Fig. $5 A)$. These results indicate that smaller varicosities tend to be less stable than larger ones and newly appeared varicosities tend to be smaller than the existing ones, both under control condition and acrobatic motor skill learning.

We next compared the fraction of these three types of varicosities between the control and acrobatic training groups (Fig. 5B). Although the fractions of both preexisting-disappeared and newly appeared varicosities were smaller in the acrobatic training group, the difference in newly appeared varicosities was statistically significant $\left(p<0.01,3 \times 2 \chi^{2}\right.$ test and subsequent residual analysis), indicating that learning primarily suppresses the formation of new varicosities. We therefore focused on newly appeared varicosities and examined their lifetime. Because it is impossible to know the lifetime of new varicosities that appeared at the last imaging session (session 5 in the control group), we only analyzed new varicosities that appeared at sessions 2,3 , and 4 and divided them into two groups: the ones that had disap- peared by the next imaging session (i.e., their lifetime was shorter than 2-3 weeks; Fig. $5 C$ ) and the others that were still present at the next imaging session (i.e., their lifetime was longer than 2-3 weeks). In the control group, 12 of 28 newly appeared varicosities had disappeared by the next imaging session, whereas only 1 of 14 newly appeared varicosities did so in the acrobatic training group. This difference was statistically significant $\left(p<0.05, \chi^{2}\right.$ test), suggesting that formation of relatively unstable varicosities was selectively suppressed during acrobatic motor skill learning, and/or newly formed varicosities were stabilized by learning. It should be noted that some of the newly appeared varicosities that had a longer lifetime than 2-3 weeks disappeared before the last imaging session, but others persisted until the last imaging session. Because it is impossible to know the lifetime of the latter ones, we did not perform further analysis for varicosity lifetime.

\section{Discussion}

There are two main findings in this study: (1) a small subset of PF axon terminals in the mature cerebellum continuously appears and disappears without any unusual sensory or behavioral stimulation (basal condition); and (2) this dynamic structural change of PF terminals is reduced during acrobatic motor skill learning, which is known to increase the number of PF-PC synapses per PC. To our knowledge, this study is the first to repeatedly observe the same presynaptic terminals in vivo in the mammalian brain during behavioral learning.

It has been shown that PF-PC synapses retain a high degree of structural plasticity in adulthood. Silencing electrical activity in the cerebellar cortex or pharmacological lesion of CFs induces formation of new PF-PC synapses in the proximal dendritic domain of PCs (CF territory in normal circumstances) (Sotelo et al., 1975; Bravin et al., 1999). Furthermore, new PF-PC synapses can be formed, even under physiological conditions (Kleim et al., 1998). Nevertheless, it is unknown whether structural plasticity of PF-PC synapses is accompanied by formation/elimination of presynaptic PF terminals. Deng and Dunaevsky (2005) performed short-term in vivo imaging (for 20 $\mathrm{min}$ ) and found that PF terminals did not show any structural changes. However, short-term imaging (minutes to hours) was likely insufficient to detect structural changes in the axon terminals. Here, we performed chronic (weeks to months) time-lapse vital imaging of PFs. Our data showed that $\sim 10 \%$ of PF terminals appeared or disappeared over the period of 2 weeks under basal conditions, suggesting that presynaptic structural plasticity can account for, at least in part, rewiring of the cerebellar circuitry.

To determine whether imaging over longer time span reveals a much larger fraction of dynamic PF varicosities, we performed chronic time-lapse imaging for $\sim 11$ months under basal condi- 
Table 1. Individual PF structural plasticity per animal under acrobatic motor skill learning $(\mathrm{AC})$ and motor activity matched control task (MO)

\begin{tabular}{lllllll}
\hline & & & & \multicolumn{2}{l}{$\begin{array}{l}\text { No. of dynamic varicosities between two } \\
\text { consecutive imaging sessions }\end{array}$} \\
\cline { 5 - 7 } $\begin{array}{llllll}\text { Animal } \\
\text { ID }\end{array}$ & $\begin{array}{l}\text { Behavioral } \\
\text { task }\end{array}$ & $\begin{array}{l}\text { No. of } \\
\text { PFs }\end{array}$ & $\begin{array}{l}\text { No. of } \\
\text { varicosities }^{a}\end{array}$ & $\begin{array}{l}\text { Before } \\
\text { the task }\end{array}$ & $\begin{array}{l}\text { During } \\
\text { the task }\end{array}$ & $\begin{array}{l}\text { After } \\
\text { the task }\end{array}$ \\
\hline 1 & AC & 1 & 4 & $0(0 / 0)$ & $0(0 / 0)$ & $2(1 / 1)$ \\
2 & AC & 2 & 18 & $5(4 / 1)$ & $0.67(0.33 / 0.33)$ & $2(1 / 1)$ \\
3 & AC & 9 & 87 & $4(0 / 4)$ & $1.67(0 / 1.67)$ & $1(0 / 1)$ \\
4 & AC & 3 & 26 & $0(0 / 0)$ & $0.67(0.33 / 0.33)$ & $0(0 / 0)$ \\
5 & AC & 4 & 32 & $7(6 / 1)$ & $1(0.33 / 0.67)$ & $5(1 / 4)$ \\
6 & AC & 1 & 11 & $1(0 / 1)$ & $0.33(0.33 / 0)$ & $1(0 / 1)$ \\
7 & M0 & 1 & 8 & $0(0 / 0)$ & $2(1.33 / 0.67)$ & NA \\
8 & M0 & 4 & 75 & $6(4 / 2)$ & $10.67(5.33 / 5.33)$ & NA \\
9 & M0 & 4 & 51 & $3(0 / 3)$ & $2.33(1.67 / 0.67)$ & NA \\
10 & M0 & 2 & 26 & $5(2 / 3)$ & $3(0.67 / 2.33)$ & NA \\
\hline
\end{tabular}

${ }^{a}$ The number of varicosities at the first imaging session.

${ }^{b}$ Numbers in these columns indicate the number of dynamic varicosities (left) and appeared/disappeared varicosities (in parentheses).

'PF structural plasticity was quantified three times (between sessions 2-3, 3-4, and 4-5) during the behavioral task, whereas only once before (between sessions 1-2) and after (between sessions 5-6) the task. Therefore, the total number of appeared/disappeared varicosities during the task (between sessions 2-5) was divided by 3 to obtain the average number of dynamic varicosities per single imaging interval for an appropriate comparison. NA, Not applicable.
A
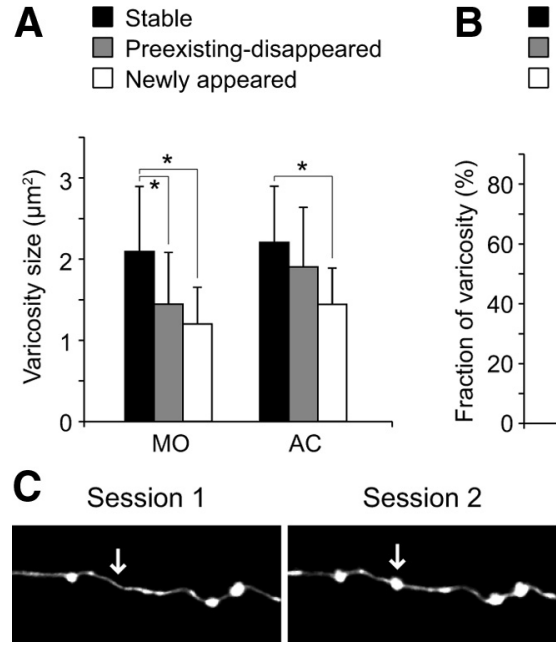

B Stable

$\square$ Preexisting-disappeared $\square$ Newly appeared

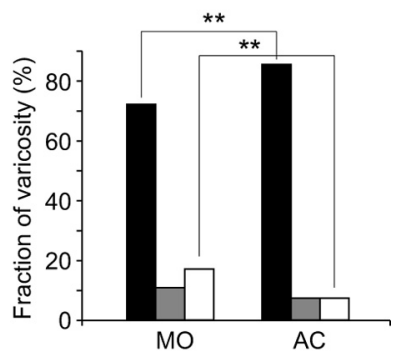

Session 3

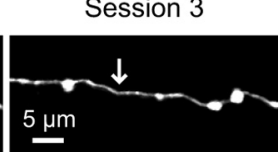

Figure 5. Acrobatic motor skill learning primarily suppresses the formation of new varicosities. $A$, The histogram represents the average size of stable, preexisting-disappeared, and newly appeared varicosities in the motor activity-matched control group (MO) and the acrobatic training group (AC). Error bars represent SD. ${ }^{*} p<0.05$. $\boldsymbol{B}$, The histogram shows the fraction of stable, preexistingdisappeared, and newly appeared varicosities in the M0 and the AC groups. ${ }^{* *} p<0.01$. C, Exemplar time-lapse images of a newly appeared varicosity that disappeared by the next imaging session. The images were taken from the $\mathrm{MO}$ group. Arrows indicate the location of the varicosity.

tions. Most varicosities $(\sim 80 \%)$ were found to be stable across this time span. In addition, most varicosities were stable when we performed 3 months of time-lapse imaging with acrobatic motor skill learning task. These results indicate that dynamic varicosities are a small fraction of the total population of PF terminals. This resembles structural plasticity of neocortical spines because they also consist of a large fraction of stable spines and a small fraction of dynamic ones (Grutzendler et al., 2002; Trachtenberg et al., 2002; Holtmaat et al., 2005; Zuo et al., 2005b). Furthermore, as most newly formed neocortical spines (60-70\%) disappear within a week (Trachtenberg et al., 2002), a large fraction of newly formed PF varicosities $(\sim 40 \%)$ have a short lifetime $(<2-3$ weeks) in the control condition.

Emerging evidence shows that structural plasticity of postsynaptic spines plays important roles in learning and memory in the mature brain. Although less is known about the presynaptic structural plasticity, a recent study showed that hippocampal and cerebellar large mossy fiber terminals increased their connectivity with local inhibitory interneurons upon behavioral learning (Ruediger et al., 2011). This initial description of learning-related axonal structural plasticity is exciting but leaves many questions unexplored. Is learning-related formation/elimination of presynaptic terminals broadly observed other than in mossy fibers? Is axonal connectivity with projection neurons also changed by learning? How does learning affect baseline level axonal structural plasticity (i.e., structural plasticity that occurs under basal condition)?

To address these questions, we observed the same PF terminals in vivo before, during, and after acrobatic motor skill learning and analyzed how presynaptic PF structural plasticity was affected by this form of motor learning. Previous electron microscopy studies revealed that acrobatic motor skill learning increases the total number of PF synapses per PC in the cerebellar paramedian lobule by increasing the volume of the molecular layer without changing the overall density of PF-PC synapses (Kleim et al., 1998). This finding prompted two important questions regarding learning-induced formation of PF-PC synapses: (1) Does the underlying structural plasticity involve only postsynaptic PCs or do presynaptic PFs also show structural changes? (2) Is the addition of synapses coupled with selective synapse loss? The latter question arises because PF-PC synapses contribute to inhibition of motor outputs (Ito, 1984), such that a unidirectional increase in these synapses would be expected to strengthen cortical inhibition of movement. However, learning-coordinated skill movements could be expected to require both the inhibition of some movements and the facilitation of others.

The present study provides important insight into these questions. Our data clearly show that acrobatic motor skill learning affects ongoing presynaptic PF structural plasticity. Interestingly, there is no net increase in PF varicosities. Rather, there is a reduction in PF structural plasticity largely through reduced addition of new varicosities, which leads to a net decrease in varicosities. The density of PF-PC synapses can remain constant even in this case if existing PF varicosities, which normally make contact with single PC spines (Pichitpornchai et al., 1994), are converted to multisynaptic terminals that make contact with several PC spines. This possibility is supported by previous findings that acrobatic motor skill training increases: (1) the relative fraction of multisynaptic PF boutons per PC (Federmeier et al., 2002) and (2) the density and length of PC spines in the cerebellar paramedian lobule (Lee et al., 2007). Moreover, learning-induced conversion from single to multisynaptic terminals is known to occur in other regions of the mammalian brain (Geinisman et al., 2001). We therefore speculate that PFs contribute to acrobatic motor skill learning by strengthening some inputs via the formation of multisynaptic terminals while maintaining the overall strength of PF synaptic drive at relatively constant levels by reducing the total number of varicosities. It remains elusive, however, how the proposed changes in PFs relate to the global increases in total number of PF-PC synapses that lead to a increase in the volume of molecular layer (Black et al., 1990; Kleim et al., 1998). Future work is required to address this point.

There are several caveats that should be noted. First, it is difficult to visualize individual PC spines in vivo largely because of their small size and high density. Therefore, we were unable to study postsynaptic structural plasticity and compare it with PF structural plasticity either in a control condition or acrobatic motor skill learning. Second, $\sim 10 \%$ of PF terminals make synap- 
tic contacts with interneurons (Napper and Harvey, 1988; Pichitpornchai et al., 1994), and dynamic properties of PF terminals might depend on their postsynaptic partner (PCs vs interneurons). However, we do not think that stable (majority) and dynamic (minority) PF varicosities reported herein simply represent PF-PC and PF-interneuron synapses, respectively. Because PC spines are highly motile (Deng and Dunaevsky, 2005), they are unlikely to provide remarkable stability to PF terminals for many months. In addition, the fraction of dynamic PF varicosities over months was $\sim 20-30 \%$ (Fig. $5 B$ ), which exceeds the fraction of $\mathrm{PF}$ terminals that make synaptic contacts with interneurons.

A large fraction of PF varicosities are anatomically stable over many months. Are they functionally stable as well, or do they show some functional plasticity? Zhang and Linden (2009) have found that functional properties of individual PF varicosities differ between small and large varicosities. Therefore, even the stable varicosities might exhibit functional plasticity if their size is dynamically changed in vivo. Unfortunately, a reliable measurement of size change is difficult in chronic in vivo imaging because apparent size of varicosities is affected by many experimental factors, such as changes in fluorescent intensity, slight brain pulsation, and angle of animal's head under the microscope. Perhaps, in vivo calcium-imaging of individual PF varicosities will be instructive to study functional plasticity of stable varicosities in the future.

In conclusion, changes in presynaptic structural plasticity underlie learning-induced rewiring of synaptic circuitry in the mammalian brain. However, our results indicate that presynaptic structural plasticity is not always enhanced by learning. We speculate that how learning affects presynaptic structural plasticity depends on how intracellular resources (such as release machinery) within axons are redistributed to reorganize synaptic circuitry. In the case of acrobatic learning, PF structural plasticity is suppressed probably because available intracellular resources within PFs are preferentially used to convert some existing varicosities to multisynaptic terminals rather than to create new varicosities.

\section{References}

Black JE, Isaacs KR, Anderson BJ, Alcantara AA, Greenough WT (1990) Learning causes synaptogenesis, whereas motor activity causes angiogenesis, in cerebellar cortex of adult rats. Proc Natl Acad Sci U S A 87:55685572. CrossRef Medline

Bravin M, Morando L, Vercelli A, Rossi F, Strata P (1999) Control of spine formation by electrical activity in the adult rat cerebellum. Proc Natl Acad Sci U S A 96:1704-1709. CrossRef Medline

Brodal A (1981) Functional neuroanatomy. New York: Oxford.

Broekman ML, Comer LA, Hyman BT, Sena-Esteves M (2006) Adenoassociated virus vectors serotyped with AAV8 capsid are more efficient than AAV-1 or -2 serotypes for widespread gene delivery to the neonatal mouse brain. Neuroscience 138:501-510. CrossRef Medline

Deng J, Dunaevsky A (2005) Dynamics of dendritic spines and their afferent terminals: spines are more motile than presynaptic boutons. Dev Biol 277:366-377. CrossRef Medline

De Paola V, Holtmaat A, Knott G, Song S, Wilbrecht L, Caroni P, Svoboda K (2006) Cell type-specific structural plasticity of axonal branches and boutons in the adult neocortex. Neuron 49:861-875. CrossRef Medline

Federmeier KD, Kleim JA, Greenough WT (2002) Learning-induced multiple synapse formation in rat cerebellar cortex. Neurosci Lett 332:180-184. CrossRef Medline

Geinisman Y, Berry RW, Disterhoft JF, Power JM, Van der Zee EA (2001) Associative learning elicits the formation of multiple-synapse boutons. J Neurosci 21:5568-5573. Medline

Grieger JC, Choi VW, Samulski RJ (2006) Production and characterization of adeno-associated viral vectors. Nat Protoc 1:1412-1428. CrossRef Medline
Grutzendler J, Kasthuri N, Gan WB (2002) Long-term dendritic spine stability in the adult cortex. Nature 420:812-816. CrossRef Medline

Holtmaat AJ, Trachtenberg JT, Wilbrecht L, Shepherd GM, Zhang X, Knott GW, Svoboda K (2005) Transient and persistent dendritic spines in the neocortex in vivo. Neuron 45:279-291. CrossRef Medline

Holtmaat A, Wilbrecht L, Knott GW, Welker E, Svoboda K (2006) Experience-dependent and cell-type-specific spine growth in the neocortex. Nature 441:979-983. CrossRef Medline

Holtmaat A, Bonhoeffer T, Chow DK, Chuckowree J, De Paola V, Hofer SB, Hübener M, Keck T, Knott G, Lee WC, Mostany R, Mrsic-Flogel TD, Nedivi E, Portera-Cailliau C, Svoboda K, Trachtenberg JT, Wilbrecht L (2009) Long-term, high-resolution imaging in the mouse neocortex through a chronic cranial window. Nat Protoc 4:1128-1144. CrossRef Medline

Ito M (1984) The cerebellum and neural control. New York: Raven.

Jones TA, Chu CJ, Grande LA, Gregory AD (1999) Motor skills training enhances lesion-induced structural plasticity in the motor cortex of adult rats. J Neurosci 19:10153-10163. Medline

Kleim JA, Swain RA, Armstrong KA, Napper RM, Jones TA, Greenough WT (1998) Selective synaptic plasticity within the cerebellar cortex following complex motor skill learning. Neurobiol Learn Mem 69:274-289. CrossRef Medline

Knott GW, Holtmaat A, Wilbrecht L, Welker E, Svoboda K (2006) Spine growth precedes synapse formation in the adult neocortex in vivo. Nat Neurosci 9:1117-1124. CrossRef Medline

Lee KJ, Jung JG, Arii T, Imoto K, Rhyu IJ (2007) Morphological changes in dendritic spines of Purkinje cells associated with motor learning. Neurobiol Learn Mem 88:445-450. CrossRef Medline

Majewska AK, Newton JR, Sur M (2006) Remodeling of synaptic structure in sensory cortical areas in vivo. J Neurosci 26:3021-3029. CrossRef Medline

Napper RM, Harvey RJ (1988) Number of parallel fiber synapses on an individual Purkinje cell in the cerebellum of the rat. J Comp Neurol 274:168-177. CrossRef Medline

Nishiyama H, Fukaya M, Watanabe M, Linden DJ (2007) Axonal motility and its modulation by activity are branch-type specific in the intact adult cerebellum. Neuron 56:472-487. CrossRef Medline

Pichitpornchai C, Rawson JA, Rees S (1994) Morphology of parallel fibres in the cerebellar cortex of the rat: an experimental light and electron microscopic study with biocytin. J Comp Neurol 342:206-220. CrossRef Medline

Ruediger S, Vittori C, Bednarek E, Genoud C, Strata P, Sacchetti B, Caroni P (2011) Learning-related feedforward inhibitory connectivity growth required for memory precision. Nature 473:514-518. CrossRef Medline

Sotelo C, Hillman DE, Zamora AJ, Llinás R (1975) Climbing fiber deafferentation: its action on Purkinje cell dendritic spines. Brain Res 98:574-581. CrossRef Medline

Stettler DD, Yamahachi H, Li W, Denk W, Gilbert CD (2006) Axons and synaptic boutons are highly dynamic in adult visual cortex. Neuron 49: 877-887. CrossRef Medline

Trachtenberg JT, Chen BE, Knott GW, Feng G, Sanes JR, Welker E, Svoboda $\mathrm{K}$ (2002) Long-term in vivo imaging of experience-dependent synaptic plasticity in adult cortex. Nature 420:788-794. CrossRef Medline

Xu T, Yu X, Perlik AJ, Tobin WF, Zweig JA, Tennant K, Jones T, Zuo Y (2009) Rapid formation and selective stabilization of synapses for enduring motor memories. Nature 462:915-919. CrossRef Medline

Yamahachi H, Marik SA, McManus JN, Denk W, Gilbert CD (2009) Rapid axonal sprouting and pruning accompany functional reorganization in primary visual cortex. Neuron 64:719-729. CrossRef Medline

Yang G, Pan F, Gan WB (2009) Stably maintained dendritic spines are associated with lifelong memories. Nature 462:920-924. CrossRef Medline

Zhang W, Linden DJ (2009) Neuromodulation at single presynaptic boutons of cerebellar parallel fibers is determined by bouton size and basal action potential-evoked Ca transient amplitude. J Neurosci 29:15586-15594. CrossRef Medline

Zuo Y, Yang G, Kwon E, Gan WB (2005a) Long-term sensory deprivation prevents dendritic spine loss in primary somatosensory cortex. Nature 436:261-265. CrossRef Medline

Zuo Y, Lin A, Chang P, Gan WB (2005b) Development of long-term dendritic spine stability in diverse regions of cerebral cortex. Neuron 46:181189. CrossRef Medline 